\title{
Las madres y su rol educador: una experiencia de cambio desde la educación popular*
}

\author{
Mothers and their Role as Educators: A Changing Experience from Popular Education \\ Jeison Alexander González Sara Alejandra González ${ }^{2}$ Nataly Quiroga Loaiza ${ }^{3}$
}

Para citar este artículo: González, J. A.; González, S. A.; Quiroga, N. (2017). Las madres y su rol educador: una experiencia de cambio desde la educación popular. Infancias Imágenes, 16(1), 25-42.

\section{Resumen}

La práctica pedagógica dentro del proyecto de Ámbito Familiar de la SDIS ${ }^{4}$ evidenció cómo los beneficiarios están condicionados al consumismo de ayudas sociales, al estancamiento en sus condiciones de vida, alejados de posturas que les permitan superar su vulnerabilidad. Aun así, a partir del desarrollo de encuentros pedagógicos mediados por la pedagogía popular, se construyeron espacios de diálogo y reformulación de saberes, lo que permitió que las madres participantes empoderaran su pensamiento a través de la reflexión constante con el otro. Dicha interacción fomentó el autoconocimiento de realidades, para que se reestructuraran y se construyeran saberes nuevos; además, estimuló un cambio en su condición de vida, las ubicó en una postura crítica, las formó como sujetos de derecho, que no se limitan al consumismo desmesurado, sino que por medio de sus habilidades y destrezas crean herramientas que les permiten surgir como ciudadanas activas, con voz y voto dentro de su vida y la de sus hijos.
Recibido: 01-agosto-2016 / Aprobado: 15-marzo-2017

Palabras clave: educación integradora; ambiente educacional; política pública; enseñanza; segregación escolar; integración escolar; educación familiar.

\section{Alostract}

Pedagogical practice within the familiar ambience project of the SDIS, showed how beneficiaries are conditioned to consumerism of social assistance, stagnation in their living conditions, away from positions that allow them to overcome their vulnerability. Even so, from development of pedagogical meetings mediated by popular education, spaces of dialogue and reformulation of knowledge were built, which allowed participating mothers to empower their thinking through constant reflection with others. This interaction encouraged self-knowledge of realities, so that new knowledge is restructured and constructed. In addition, it stimulated a change in their living condition, placed them in a critical position, formed them as subjects of law, not limited to excessive consumerism, but through their

\footnotetext{
* Artículo reflexivo, realizado a partir de la práctica laboral de las maestras Sara González y Nataly Quiroga en el proyecto Ámbito Familiar de la Secretaría de Integración Social de Bogotá en la localidad de Bosa, investigación que se realiza a favor de la Licenciatura en Pedagogía Infantil de la Universidad Distrital Francisco José de Caldas, iniciando el 2 de febrero de 2014 y finalizado el 5 de diciembre de 2014.

1 Licenciado en Pedagogía Infantil. Magíster en Educación. Estudiante del Doctorado en Educación, Universidad Internacional Iberoamericana UNINI - México. Docente área de lenguaje de la Licenciatura en Pedagogía Infantil, Universidad Distrital Francisco José de Caldas. Correo electrónico: jeison.gonzalez@javeriana.edu.com

2 Licenciatura en Pedagogía Infantil, Universidad Distrital Francisco José de Caldas. Correo electrónico: alejag9@gmail.com

3 Licenciatura en Pedagogía Infantil, Universidad Distrital Francisco José de Caldas. Correo electrónico: natykquiroga@gmail.com

4 Secretaría Distrital de Integración Social del Distrito Capital, Bogotá.
} 
skills and abilities to create tools that allow them to emerge as active citizens with voice and vote in their lives and their children's.

Keywords: inclusive education; educational environment; government policy; teaching; school segregation; school integration; family education.

\section{Introducción}

La maternidad y la formación de una familia para algunas personas puede considerarse un estilo de vida al que una mujer puede acogerse después de haberse preparado para ello, es decir, después de haber culminado una carrera profesional, tener una edad determinada, contar con un trabajo fijo, una pareja estable e, incluso, una vivienda propia. Esta podría considerarse una realidad para muchas comunidades, pero en una época como la actual, en la que los jóvenes obtienen información descontrolada sobre el cuerpo y el sexo por parte de los medios de comunicación, se evidencia lo contrario,

y si se observa cómo día a día aumentan las tasas de embarazos adolescentes, como lo cita El Espectador (2014): "desde 2008 hasta 2013 han nacido cada año, en promedio, 159.656 niñas y niños de madres entre 10 y 19 años" (p. 1) , en todo el país, según datos reportados por el DANE. Dichas cifras ubican a Bogotá, como una de las ciudades con más alto índice de embarazos a temprana edad.

En concordancia con esto, en el contexto de la localidad de Bosa, al suroccidente de la capital, es posible encontrar un imaginario ${ }^{5}$ en común entre las madres que forman parte del proyecto Ámbito Familiar, del cual hablaremos más adelante. Las madres participantes que han estado en embarazo a temprana edad, o que cuentan con familias numerosas en las que escasean los recursos económicos, consideran que el Estado debe ser quien les garantice un sustento económico para sobrellevar su maternidad, creen que el hecho de ser madre garantizará un beneficio social y que cuantos más hijos tengan mayor va ser el valor de los subsidios que se reciben.

\footnotetext{
Imaginarios puede definirse como aquellas representaciones personales utilizadas para designar aspectos sociales, también, es usado cotidianamente como sinónimo de mentalidad, cosmovisión, conciencia colectiva o ideología personal (Castoriadis, 1993).
}

Este factor, junto con el aumento de embarazo adolescente, ubica a los sujetos en hogares que no cuentan con todas las herramientas necesarias para el cuidado adecuado de los niños entre los 0 y 3 años, razón por la cual es necesario priorizar el apoyo que se le brinda a dicha población, ya que según lo reportado en el informe de la Secretaría Técnica del Consejo Distrital de Política Social (2014), "en esta franja de edad el $71 \%$ de las familias prefieren tener el bebé en casa antes de Ilevarlo a un lugar de atención" (p. 8).

Así, surge el proyecto Ámbito Familiar ${ }^{6}$, como una estrategia de la política pública para brindar apoyo personalizado a cada familia con gestantes menores de edad, o con niños y niñas menores de 3 años. Dicha estrategia de atención integral se ha caracterizado por reducir las situaciones que afectan a la primera infancia a través de un "constante acompañamiento en pro de generar cambios en las pautas de crianza, alimentación y la vinculación de escenarios de desarrollo infantil directos en las familias de las zonas más segregadas" (p. 8). Dicho acompañamiento es dirigido por profesionales que toman por iniciativa propia a la educación popular, como modelo de trabajo, para alcanzar su objetivo, puesto que esta puede ser asumida como un método de alfabetización concientizador, lejano al método "bancario" que solo pretende adoctrinar, sino que se plantea, como una propuesta de "la educación como práctica de libertad" (Freire, 1997), en la que se logre integrar al sujeto con sus vivencias, de forma que sea capaz por sí mismo de reevaluar y comprender las causas de su realidad social.

Siendo Bogotá pionera en la ejecución del proyecto, dentro del "Plan de Desarrollo Económico, Social y de Obras Públicas para Bogotá Humana 2012-2016", en complementariedad con el Gobierno nacional, de acuerdo con el artículo 137 de la Ley 1450 de 2011, Plan Nacional de Desarrollo

\footnotetext{
6 Ámbito Familiar forma parte del proyecto 735 de la Secretaría Distrital de Integración Social (SIDS), su objetivo es potenciar el desarrollo integral de los niños y niñas de primera infancia en Bogotá, desde un modelo inclusivo y diferencial de calidad, y acciones que garanticen el cuidado calificado, experiencias pedagógicas significativas, disfrute del arte, cultura, juego, actividades físicas, promoción de vida y alimentación saludables, además de la generación de ambientes adecuados, seguros, sensibles y acogedores.
} 
2010-2014 y dado que está mediado principalmente por el factor económico, puesto que se da a conocer a la comunidad a través de un apoyo nutricional, en el que cada participante inscrita podrá reclamar un bono canjeable por alimentos de la canasta familiar, se reflexionó en torno a la pregunta: ¿Cómo logran las madres participantes del proyecto Ámbito Familiar de la SDIS de la localidad de Bosa empoderar su pensamiento, transformar sus imaginarios y generar un cambio en la condición de vida de sus hijos como primeras educadoras desde al acompañamiento de una perspectiva pedagógica y no de un complemento monetario de un programa social?

\section{Definición del problema}

En la actualidad, el campo de acción de la pedagógica infantil se ha ampliado a diferentes ámbitos, así el rol de sus profesionales en programas de integración social ha tomado un valor y acción fundamentales para la educación, atención y cuidado de las infancias; así, en el Distrito Capital (Bogotá) se ha generado, desde la filosofía de Estado de bienestar, un conjunto de estrategias para las personas beneficiarias de programas sociales, donde el Estado mitiga un poco el dolor y el sufrimiento, pero no da solución al problema, como es el caso de la desnutrición en Colombia.

Este problema ha afectado a muchos y otros tantos lo comentan, pero no ha tenido solución. Por ejemplo, en datos obtenidos por la Dirección de Epidemiología y Demografía del Ministerio de Salud (2015)

[...] durante el periodo comprendido entre 2009 y 2014 las condiciones transmisibles y nutricionales generaron el 43,56\% (11.007.360) de las atenciones, fueron la causa que mayor cantidad demandó en este grupo de edad; en total se atendieron 2.165.068 personas por esta causa, para una razón de 5,08 atenciones por persona. (p. 96).

En estas atenciones se observó una baja nutrición y desinformación sobre una alimentación saludable.

Cuando esta población se clasifica dentro de diagnósticos, como el bajo peso o desnutrición, acude a entidades como la SDIS a buscar apoyo, ayudas sociales que les permitan mejorar o sobrellevar su condición. Así se encuentran con programas como Ámbito Familiar, en el que se prioriza la necesidad de cada participante y se le brinda apoyo económico canjeable por alimentos, que fomenten la adecuada nutrición de los niños. De esta forma se mitiga el problema y se adoctrina a la población en el conformismo, puesto que el Estado se convierte en un proveedor inmediato de aquello que necesita el beneficiario, pero no se concentra en concientizar a esos sujetos sobre su realidad, sobre cómo puede crear estrategias que le ayuden a transformar su vida y a progresar por sí mismo, para que el apoyo recibido sea temporal, y que una vez el individuo pueda valerse por sí mismo, este beneficio pueda ser entregado a un tercero.

Los proyectos sociales están formando a la sociedad para que no luche por sus derechos, para que se limite a consumir, no a producir; no se practica, como diría Paulo Freire (1970), "la pedagogía del oprimido", en la que sujetos deben tener una visión crítica del mundo en el que viven, con el fin de liberarse de aquellas fuerzas opresoras que los encasillan y limitan en unas condiciones de vida que solo benefician a unos pocos. Dicha pedagogía tradicional bancaria, de la que se apropian los privilegiados, no permite a los oprimidos ser, alcanzar su libertad para convertirse en hombres nuevos; en el que el bienestar de su sociedad no esté basado en la dominación y explotación de unos hombres sobre otros. Si dentro de los programas sociales se apropia este tipo de pedagogía, los beneficiarios estarían inscritos de manera momentánea, mientras consiguen o construyen nuevas herramientas para mejorar su realidad; pero lo que se evidencia es que, una vez se convierten en beneficiarios de ayudas del Estado, permanecen en su condición indefinidamente.

Así, se sigue encontrando en la sociedad, y específicamente en la localidad de Bosa, según datos de la Alcaldía Mayor de Bogotá (2009) "consumo de sustancias psicoactivas, lesiones personales con arma blanca, hurto, barras futboleras" (p. 70). Esto propicia la formación de familias en las que predominan los conflictos, la mala conducta, problemas 
de comunicación e, incluso, abuso o maltrato por parte de uno de los miembros hacia los demás; estas, a su vez, no cuentan con redes de apoyo social, poseen escasos ingresos económicos, analfabetismo, desempleo, niños y niñas entre los 0 y los 3 años de edad en escenarios de maltrato, desnutrición, abandono, trabajo infantil, abuso físico y sexual. Esta "disfuncionalidad familiar recae en la pérdida de la capacidad familiar para mantener el equilibrio emocional de sus integrantes" (Alcaldía Mayor de Bogotá, 2009, p. 74).

Esta población vulnerable es prioridad del proyecto Ámbito Familiar, el cual pretende lograr una transformación en los imaginarios sociales de los participantes, entre otros: a) la concepción de niño como una persona que requiere únicamente asistencia permanente, de la cual no se puede aprender, sino a la que se le deben enseñar estrategias para la vida; b) la educación como elemento propio de la escuela, por lo que en la casa la atención se centra en el cuidado permanente y a la realización de las tareas diarias del hogar; c) el juego visto solo como elemento de esparcimiento y diversión; d) la idea de la mujer ama de casa como individuo sin derechos, ni posibilidades de progreso, dada su limitación para brindar un apoyo económico al jefe del hogar.

La transformación de estas miradas de mundo solo puede ser lograda, como diría Freire (1970), a través de la problematización, de la construcción y deconstrucción de saberes que permitan descubrir y comprender la realidad en la que se vive, el compartir las ideas unos con otros conlleva a la socialización y, a su vez, contribuye a que las madres o cuidadoras puedan empezar a ver a sus hijos como sujetos de derecho y verse a sí mismas como sujetos activos dentro de la sociedad que no solo proporcionan alimento y cuidado, sino que son las encargadas de forjar el pensamiento, la personalidad, los comportamientos y el desarrollo integral de esos seres que dependen de ellas. Romper con la pasividad y el silencio es el ideal desde la pedagogía popular, cuando se educa desde el diálogo con una visión consciente, se educa políticamente, se modifica la realidad formando ciudadanas activas que ejercen sus derechos y cumplen con sus deberes.
Para ampliar la comprensión del contexto de este programa es necesario decir que Ámbito Familiar es el proyecto de atención integral a la primera infancia y madres gestantes en espacios no formales del Distrito Capital. Como su nombre lo indica, se desarrolla en la familia, está dirigido a niños y niñas que no se encuentran escolarizados, ni en jardines infantiles. Son niños y niñas cuidados en sus hogares, cuidados por sus madres y abuelas quienes se van formando periódicamente en los encuentros pedagógicos grupales y domiciliarios ${ }^{7}$ como las primeras educadoras de sus hijos.

El fundamento legal se inicia con el plan de gobierno propuesto por el exalcalde Gustavo Petro ${ }^{8}$, donde se presentan los territorios saludables y la atención integral a la primera infancia desde el ámbito institucional y el familiar. Estas dos modalidades constituyen el Proyecto 735 Ilevado a cabo por la Secretaría Distrital de Integración Social (SDIS).

El ámbito institucional pretende "garantizar la atención a niños y niñas en jardines infantiles a cargo de la SDIS, con estándares de calidad y el lineamiento pedagógico de la educación inicial" (SDIS, 2013, p. 11). Por medio de una educación incluyente —que promueva ambientes adecuados y seguros para el desarrollo de los niños y niñas, mientras se fortalece el desarrollo familiar y comunitario-, se espera que los niños y niñas menores de 2 años reciban una la atención integral

\footnotetext{
Encuentros pedagógicos grupales: son espacios de construcción pedagógica donde se llevan a cabo objetivos frente al desarrollo integral del niño, niña y madre gestante; se realizan 5 actividades en un espacio de 3 horas. Estos encuentros se dan, en su mayoría, en los salones comunales de los barrios a los que pertenecen las familias participantes y se realizan una vez por semana, acompañados de la dupla pedagógica, luego el psicosocial y el nutricionista, y de los profesionales de cultura por parte de Idartes. Son de aproximadamente 50 familias participantes repartidas en tres grupos de 16, y van ligados a las actividades que se realizan en los domicilios con la dupla pedagógica; la asistencia a estos encuentros está mediada por la entrega del bono de apoyo nutricional.

Los encuentros pedagógicos domiciliarios los realizan las duplas pedagógicas, quienes visitan a la familia en el domicilio tres veces en el mes para hacer un acompañamiento oportuno, estableciendo supervisión de los ambientes sanos y seguros, como también leer la realidad de la familia y la crianza que tiene el niño, procurando así la restitución de derechos y comunicando de manera oportuna en las rutas de acción, por si se presenta vulneración, maltrato, abandono.

8 Plan de Desarrollo Económico y Social y de obras públicas para Bogotá Distrito Capital 2012-2016 Bogotá Humana.
} 
para el crecimiento saludable, a través de procesos pedagógicos, nutricionales, salud y cultura, la corresponsabilidad de los padres o cuidadores, la promoción del ambientes adecuados para el desarrollo de la primera infancia en el marco de una educación inicial inclusiva, diversa y de calidad.

Ámbito Familiar garantiza el desarrollo integral y potencia las capacidades de los niños, por medio de intervenciones de tipo: nutricional, pedagógica y de formación a familias, de esta forma fortalece la atención desde la gestación, con el fin de construir y fortalecer los vínculos afectivos (SDIS, 2013). Además, implementa estrategias que buscan generar condiciones de seguridad y protección tanto en la casa como en el entorno inmediato de los menores.

Dentro de esta modalidad, se desarrollan encuentros pedagógicos domiciliarios y grupales acordes a las características e intereses de las familias participantes, que fortalezcan su compromiso con el desarrollo de sus hijos. Así mismo, en el componente nutricional se busca la seguridad alimentaria de los niños, mediante la entrega de apoyos que propicien una alimentación balanceada, hábitos nutricionales y una vida saludable.

La intención inicial del proyecto es la cobertura alimentaria a los niños menores de 3 años y madres gestantes, reduciendo a cero las cifras de morbilidad infantil por desnutrición en Bogotá. De esta manera se potencia el desarrollo integral de los niños de primera infancia en Bogotá, desde un modelo inclusivo y diferencial de calidad y acciones que garanticen el cuidado calificado, experiencias pedagógicas significativas, disfrute del arte, cultura, juego, actividades físicas, promoción de vida y alimentación saludables, y la generación de ambientes adecuados, seguros, sensibles y acogedores (SDIS, s.f.).

Bajo dicho propósito, las familias están acompañadas por un equipo interdisciplinar: dos maestras del área de infancia, un psicosocial, un nutricionista y una dupla de cultura a cargo del Instituto Distrital de Ates (Idartes). Estos se articulan semanalmente en la atención de cada familia, reportando casos específicos a cada profesional para así cumplir con los objetivos contractuales de restitución de derechos a la infancia, prevención y atención de casos de vulneración por abandono, maltrato físico, verbal, psicológico, sexual; además, la restitución del papel de la mujer como sujeto de derecho, cuidadora y maestra de su hijo como un privilegio y no una carga o castigo.

\section{Consideraciones teóricas}

A continuación se evidencian algunas concepciones teóricas utilizadas para el análisis y reflexión de nuestra práctica laboral con los niños y familias participantes del proyecto de Ámbito Familiar.

\section{Estado de bienestar}

Desde este punto podría decirse, además, que el programa Ámbito Familiar surge con el fin de crear un Estado de bienestar en la sociedad a partir de un proceso pedagógico. Por Estado de bienestar se conoce a la capacidad de cubrir las necesidades sociales, pero esto solo puede existir si se activa la necesidad de consumo de los ciudadanos, si se evidencia la demanda de un servicio.

Como lo propone Montagut (2000), el Estado tiene el deber de procurar los medios de subsistencia a los ciudadanos menos afortunados, razón por la cual, por ejemplo, se han creado lugares para atender a las personas que por diferentes razones deambulaban las calles sin trabajar, convirtiéndolas en beneficiarias eternas, sin la autonomía necesaria para superar su propia condición. Esta falta de autonomía podría tratar de atenderse o invisibilizarse gracias al principio de caridad de los demás ciudadanos, en el que si alguien tiene hambre se le da dinero, si tiene frío se le da dinero y si no tienen hogar también se le da dinero; pero no dinero en abundancia, sino en cantidades mínimas, en forma de las tan mal Ilamadas "limosnas", que le permitan al beneficiario salir de su condición momentáneamente.

La caridad era, y sigue siendo, el vehículo primario de asistencia y protección social, pero esta, sin la atención individualizada que ayuda a las víctimas de la pobreza a volver a una vida normal y productiva, suele conducir al fracaso. Por esta razón, si solo se habla de ayudas sociales desde un Estado de bienestar como proveedor constante, el sujeto afectado, en este caso las madres participantes, pierde su derecho a ser sujeto activo, y su voz 
queda relegada al conformismo del mero consumismo. Pensar en el empoderamiento de la mujer debe ir más allá, debe estar ligado con la transformación de realidades, para que el bienestar brindado por el agente político sea temporal y sirva de trampolín para una vida autónoma y productiva.

La política social no es más que uno de los ámbitos de las transformaciones que se registran en la democracia de cada sociedad y en los que se revela la presencia de limitaciones institucionales, y a pesar de que se intenten construir herramientas para mitigar las desigualdades sociales, la necesidad de los ciudadanos termina convirtiéndose es un círculo vicioso que cada día se llena de más participantes y de más necesidades, pues esta

[...] tiene un carácter meramente marginal, ya que continúa caracterizándose por una preocupación por "contener" la pobreza mediante la implementación de una función "subsidiaria", asumiendo para ello un estilo asistencial-clientelista, pero esquivando el punto de lo que debiera ser su preocupación central: la existencia de la inequidad social y la generación de empleo productivo como condiciones indispensables para lograr una mayor inclusión social. (Ciancio, s.f., p. 23).

En ese sentido, los individuos tienen el imaginario frente al asistencialismo del Estado como una caridad, como algo que debe proporcionarse de manera permanente y obligatoria, sin limitantes y, de ser posible, de forma económica.

Todo lo anterior se debe a la pérdida de la calidad de sujeto de derecho, de aquello que los ciudadanos merecen y necesitan, de la diplomacia de los entes de poder, para satisfacer necesidades en vez de crear oportunidades. De allí surge la idea de derecho social, como una estrategia del poder político para reparar los perjuicios causados por la división social, mas no como una forma de reorganizar la sociedad, mitigando la injusticia original, en la que las clases altas, tienen mejores oportunidades, y los menos favorecidos solo son sometidos, son llevados por el camino de la inequidad y el asistencialismo (Donzelot, 2007).

Este desmonte de los derechos sociales, en la que la calidad de sujeto, como ciudadano autosuficiente con igualdad de condiciones se invisibiliza, le quita el verdadero sentido a la política pública, puesto que en vez de dignificar y propiciar el crecimiento de la sociedad, asiste, invalida y segrega a los participantes de proyectos como Ámbito Familiar, dejándolos a merced de un apoyo económico, al que tienen acceso, si cumplen con ciertos criterios de calidad de vida y de participación ciudadana, lo que podría compararse con la relación, oferta/cliente, en la que las madres y familias vinculadas se convierten en clientes consumidoras de un apoyo económico, un bono alimentario.

Si el Estado formara a los sujetos políticamente, sabrían cuestionar aquello que les dan, para no verlo como una caridad sino como un derecho, pero un derecho que requiere de un deber, un deber ser, el deber de suplirse temporalmente mientras encuentra la manera precisa de solventar su situación por sus propios medios, para dejar de depender, para empezar avanzar, para continuar y no seguir bajo el principio de caridad. La política pública no debería cumplir una función asistencialista, sino que debería educar a sus beneficiarios para que construyan sus propias herramientas para satisfacer sus necesidades.

Y es en este punto donde se suscita la educación popular como la posibilidad de salirse de lo cotidiano para revolucionar el proceso de enseñanza y aprendizaje de la sociedad. Podemos decir que la educación popular forma parte de los procesos políticos-pedagógicos que buscan superar las relaciones de dominación, opresión, discriminación, explotación, inequidad y exclusión, a través de la noción de pueblo político donde se lucha por eliminar dichas diferencias. Así se construyen relaciones equitativas y justas, diversas, igualitarias y respetuosas en la diversidad, y se restituyen los derechos de todos los ciudadanos (Gallardo, 2006).

Freire (1993) comenta que, como seres humanos, aprendemos en todos los contextos de manera continua, ya sean cosas positivas o negativas, por ello es importante formar en la función pedagógica reconociendo lo que necesitamos para brindar un servicio de calidad, no por un año escolar o el cumplimiento de un programa social, sino una educación para la vida. Y es que el campo de saber de la educación y de la pedagogía nos muestra muchas 
perspectivas, una de ellas la progresista, en la que el maestro es visto como un educador político que forma ciudadanos para una sociedad, que pretende no buscar un bien propio, sino generar también un bien común. Por lo cual, este debe desempeñar y desarrollar sus cualidades en la convivencia con otros individuos, en un sistema democrático que permita expresar y escuchar para poder decidir, cambiando el discurso unilateral y autoritario, del que sabe y el que requiere saber.

El maestro progresista debe, además, desarrollar una facultad de amor y respeto, puesto que los programas sociales están dirigidos a las personas más vulnerables. Poder tolerar en la diferencia contemplando a los demás como seres únicos y valiosos, sujetos de derechos que necesitan de los espacios de formación familiar, es vital para desarrollar sus facultades como primeros educadores y construir o encaminar su proyecto de vida. Estos espacios deben propiciar una educación democrática, crítica y liberadora que contribuya a formar sujetos con las destrezas para transformar sus relaciones sociales y con el mundo; una educación domesticante, alienadora y autoritaria inhibe la construcción de sujetos autónomos (Freire, 1970).

A partir de allí, para construir sujetos autónomos, formados políticamente se requiere de ejercicios de lectura y escritura crítica, en los que no se fragmente la información del mundo, sino que se analice, se digiera y se reconstruya.

\section{El rol de la madre}

La familia, al ser el primer contacto con la sociedad, cumple un papel importante en el desarrollo de los hijos, puesto que tiene el poder de reestructurar la concepción de niño como sujeto, promover la formación de sujetos críticos, que reelaboran las pautas de crianza y, además, pueden centrar a las madres como primeros cuidadores, como sujetos con voz y voto, transformándolos en sujetos de derecho dentro de la familia y la sociedad.

Antiguamente se pensaba que una mujer estaba destinada a dar vida, criar a sus hijos, atender a su esposo y dedicarse de lleno a las labores del hogar; sin descalificar dicho planteamiento, podría decirse lo desactualizado que se encuentra tal idea o concepción, puesto que en una sociedad como esta, en la que vivimos bajo las presiones del tiempo y el dinero, una mujer no puede quedarse relegada a las labores domésticas, y más cuando por diversas razones se encuentra catalogada como madre soltera.

Esto ha hecho que algunas mujeres opten por salir de sus casas a buscar un sustento económico para sus familias, el cual en muchos casos no es elevado, ni constante, pero ayuda a suplir a cambio de horarios extendidos las necesidades básicas de las personas a su cargo.

En el país, las mujeres trabajan más tiempo y tienen un nivel superior en su formación académica, ganan hasta un 20,2 \% menos que los hombres, lo cual ubica al país con una de las más altas diferencias en América Latina. Incluso, análisis como el del Grupo de Género y Desarrollo del Banco Mundial hablan de una brecha adicional entre ellas mismas, que indica que en países como Colombia, Brasil, Guatemala, México, Perú y Uruguay, la diferencia salarial entre las casadas y con hijos pequeños versus otras mujeres es especialmente grande (Ramírez, 2015).

Ahora bien, como la mayoría de mujeres no deciden enfrentar dicha realidad, toman la primera opción de vida: dedicarse al hogar. Sin ser esta una mala decisión, sí condiciona mucho su vida, dado que como se evidenció con algunas participantes del proyecto de Ámbito Familiar de la SDIS, las que permanecían en sus casas haciéndose cargo de todo el cuidado de sus hijos tenían unas concepciones de vida diferentes, sentían que su opinión estaba en ocasiones limitada por la voz del aportarte económico de la familia.

Es necesario reconocer las condiciones materiales y simbólicas que mediatizan las decisiones que toman las madres frente a su vida, entre ellas incide la estabilidad laborales de los miembros del hogar, el peso de las mismas en sus condiciones generales de vida, la división del trabajo doméstico, la distribución del poder o de la autoridad intrafamiliar, el conjunto de valores y significaciones que a nivel de lo social construyen los sujetos desde su legitimización o negociación en el interior de los hogares, o también Ilamadas unidades domésticas (Ciancio, s.f.).

Según datos del Departamento Administrativo Nacional de Estadística (DANE) en el Foro Regional 
de Uso del Tiempo y Trabajo No Remunerado (2012), se expuso la necesidad de la vinculación a la economía nacional, y socializar a nivel regional, los principales lineamientos y avances en el cumplimiento de la Ley 1413 de 2010, la cual regula la inclusión de la economía del cuidado en el sistema de cuentas nacionales. Esto refleja la labor de la mujer dentro de su hogar. La economía del cuidado, como la define el artículo 2 de la Ley 1413 de 2010, hace referencia

[...] al trabajo no remunerado que se realiza en el hogar, relacionado con mantenimiento de la vivienda, los cuidados a otras personas del hogar o la comunidad y el mantenimiento de la fuerza de trabajo remunerado [y reafirma que] esta categoría de trabajo es de fundamental importancia económica en una sociedad. (Ley No. 1413, 2010, p. 1).

En 2010, el 92,4\% de las mujeres mayores de 10 años realizaron actividades no remuneradas, frente a $63,1 \%$ de los hombres, en el total nacional. En la zona rural la proporción fue más alta que en la urbana: 95,5\% frente a 91,6\%. También se conoce que horas a la semana (carga total de trabajo): hombres 61,6 horas y mujeres 72,4 . Como el trabajo no remunerado: hombres 13,1 horas, y mujeres 32,0 horas (Freire, s.f.). Se puede evidenciar la sobrecarga y desigualdad de género. La sobrecarga de trabajo de las mujeres: en el periodo 2007-2010, ellas trabajaban 10,8 horas promedio a la semana más que los hombres, en el total nacional. El trabajo no remunerado de las mujeres fue 18,9 horas más que de los hombres. A nivel nacional, entre las actividades no remuneradas, en 2010 el 92,4\% de tiempo se dedica al oficio de hogar y cuidado de personas (niños y ancianos).

Es así como los estudios sobre los "usos del tiempo" fueron determinantes para hacer visible la dimensión cuantitativa, a partir del reconocimiento de que la actividad dedicada al cuidado de la vida humana resulta ser más importante que el trabajo remunerado, en vista de que esta permite que funcione el mercado y el resto de actividades sociales. En ese sentido, las personas crecen y se desarrollan como seres humanos y como ciudadanos integrantes de una comunidad política (Ramírez, 2011).
A partir de allí, se intenta evidenciar el hecho de que las tareas del hogar atrapan y que permanecen invisibilizadas, como si se tratara de actividades que solo las mujeres, debido a su naturaleza, son capaces de llevar a cabo. A pesar de que ellas se encuentran en un contexto de igualdad formal, este es uno de los tantos campos en los que se manifiesta la discriminación femenina; puesto que lo importante no es lo que las mujeres hacen dentro de sus responsabilidades diarias (barrer, cocinar, limpiar, cuidar), sino el valor social que se gesta dentro de su deber ser. Este valor está mediado por su capacidad de transmitir valores, creencias y visiones de mundo a aquellos que las rodean a diario.

Dicha responsabilidad social continuará pasando inadvertida, hasta tanto las mujeres no se aíslen de la jerarquía masculina, y contemplen la jefatura femenina, como algo más que "ser reconocidas como 'jefas' cuando en el hogar no existe un hombre adulto" (Geldstein, 1994, p. 144) que brinde sustento y control. Es necesario que las mujeres puedan ir rompiendo las argumentaciones tradicionales basadas en el altruismo materno que implica su subordinación a las necesidades de los demás miembros de la familia, para poder reclamar su derecho como personas, como sujetos activos, con el poder de transformar y formar ciudadanos críticos.

\section{La madre como primera educadora}

La Oficina Regional de Educación de la Unesco para América Latina y el Caribe desarrolló el proyecto regional que tiene como objetivo fortalecer la participación y la educación de madres y padres, como principales educadores de sus hijos en la primera infancia (Silva, 1997). Destaca la noción de infancia y su evolución a lo largo de la historia, la alta mortalidad infantil y la fragilidad de los menores, hacía que estos tuviesen un escaso valor en términos económicos, puesto que no podían aportar recursos a la familia, por lo cual, en el contexto de la Revolución Industrial, se permitió a niños y jóvenes asumir diversos trabajos, con el fin de que los menores adquirieran un mayor valor en términos de un seguro para la vejez.

En este periodo la familia era entendida como una sociedad que aseguraba la supervivencia de sus miembros, y no se le veía como un espacio de 
afecto. Las primeras preocupaciones respecto a qué hacer con los niños en sus primeros años corresponden a ideas de pedagogos clásicos, como: J. A. Comeniu, J. Rousseau y J. Pestalozzi. Los conceptos pedagógicos de estos pioneros en la educación de los niños difieren entre sí en aspectos como la educación libre o la educación dirigida; la educación familiar o la educación social; los métodos de educación y enseñanza en las primeras edades; sin embargo, todos subrayaron la enorme importancia que tiene la educación de los niños en las edades tempranas y su vinculación con su posterior aprendizaje y desarrollo.

Esta nueva idea de familia genera un estado de preocupación por el bienestar del niño, y a su vez invita a que este debe ser visto como un ser distinto del adulto, con características propias. Suscita el nacimiento del amor maternal como construcción social, ya que las madres en ese momento no manifestaban dicho amor como algo instintivo:

En 1780 solo 1000 de los 21.000 bebés nacidos cada año en París eran amamantados por sus madres. Otros 1000 recién nacidos, los niños de las familias privilegiadas, eran amamantados por nodrizas fuera de París. Muchos morían ante lo que hoy consideraríamos indiferencia de los padres, quienes frecuentemente ignoraban el paradero de sus hijos. (Reveco, 2002. p 5).

A partir de estas situaciones, se empiezan a concebir reflexiones y propuestas de ciertos educadores, en las que la infancia aparece como una edad con características propias y la familia como un espacio de protección, cuidado y educación de los hijos. Aquí, la relación entre educación y familia empieza a aparecer como un desafío para la educación, puesto que "el niño o niña no vive aisladamente, convive, vive con una familia y en una comunidad, en una determinada cultura; por ende, hablar de educación es consustancial a la educación del niño pequeño, la educación con la familia y la comunidad del infante" (Reveco, 2002, p. 9). Es así como el desarrollo humano es de carácter interactivo, sucede gracias a las relaciones entre personas, donde el afecto y la comunicación desempeñan un rol fundamental.
Para que esto suceda adecuadamente, se deben considerar dentro del desarrollo del niño estímulos diversos, desde la parte afectiva, auditiva, visual o de movimiento, que faciliten una educación a través de los sentidos. Por lo cual un ambiente familiar pobre en afecto dificulta el adecuado desarrollo, desencadenando el fenómeno denominado síndrome del niño institucionalizado (Unesco, 2004), en el cual no se habla a los niños, se valora la pasividad o se prohíbe tocar objetos, inhibiendo así las posibilidades de adquirir saberes, de conocer el mundo, de forjar un pensamiento propio.

Estas costumbres familiares inapropiadas o escasamente favorecedoras del aprendizaje afectan negativamente la formación del niño, por la cual sea necesario que las pautas de crianza y la información que posea la familia puedan facilitar y no obstaculizar el desarrollo infantil.

Reveco (2002) destaca la centralidad de los padres en la educación de sus hijos, y el hogar como espacio fundamental de aprendizaje, especialmente en el caso de los más pequeños, así como la necesaria articulación y complementariedad entre las familias y las instituciones educativas. Los primeros educadores de los niños son las madres y los padres, el espacio de aprendizaje por excelencia es el hogar, el barrio, la comunidad, la ciudad. El jardín infantil, la escuela y el colegio continúan, fortalecen, potencian o enriquecen con su conocimiento especializado lo que la familia y el contexto han iniciado.

Desde este punto, se debe posibilitar a las madres la transformación de los imaginarios frente a su rol en el hogar, es aquí donde la educación popular desempeña un papel importante en el autorreconocimiento como sujetos, para lograr empoderar así su accionar frente a sus hijos y la sociedad, sin el condicionamiento de un trabajo formal o una carrera, ya que el único oficio para el que no existe título ni acreditación exigible, es el más noble y difícil de todos: el rol de padre o madre de sus hijos. Posibilitar, además, que la madre pueda reconocer que su presencia, su voz, su arrullo y la enseñanza de la lengua materna, son las bases para el desarrollo integral de sus hijos como ciudadanos sujetos de derechos. 
La maternidad deja entonces de ser un hecho individual, se sale del ámbito de lo privado para ingresar en el terreno público, ya que la socialización de la maternidad, de la crianza y el despertar la conciencia de que los hijos no son propios de la madre, sino de toda la sociedad, hace que el crecimiento y desarrollo de cada niño sea una responsabilidad colectiva. Este hecho implica un posicionamiento político acerca de cómo concebimos la condición humana, qué tipo de sujetos ayudamos a desarrollar y, por ende, qué tipo de sociedad apuntamos a construir. (Rosemberg, 2009).

Allí radica la importancia de recuperar la voz de la madre que ha sido subordinada, y generar espacios de participación donde se establezca el pensamiento cultural frente a los discursos autoritarios, pues participar supone la posibilidad de incidir, decidir, opinar, aportar y disentir, es decir, ejercer una acción política, ya que para participar se debe contar con el poder para que la voz de quien habla tenga un estatus que le permita ser escuchada y cuyas ideas, opiniones y acciones tengan la posibilidad de influir. Para que esto sea posible, se requiere de una pedagogía crítica para construir una referencia educativa alternativa a la dominante, que no comunique conocimientos, sino que modifique actitudes y desarrolle aptitudes críticas frente a la realidad. El aprendizaje es una cuestión política, lo que nos constituye como sujetos activos, de acción, para poder reestructurar las condiciones internas de cada uno y transformar el medio externo al comprender que las limitaciones en el desarrollo de estas subjetividades están condicionadas fundamentalmente desde un orden social (Pichon Rivière, 1984).

Dado que el sujeto no nace, sino que se hace en comunión con su realidad inmediata, podría decirse que es fundamental dar visibilidad político-social a la problemática del desarrollo infantil y a la madre, para que así pueda tomar conciencia de las características y necesidades específicas de la niñez. La infancia más temprana, los primeros años de vida, constituye la etapa donde se sientan las bases de la persona, allí se determinan los primeros aprendizajes y las primeras interacciones sociales. En esta etapa se estructuran las bases de un futuro ciudadano, que puede ser: un sujeto autónomo, con criterios propios de decisión, solidario, cooperativo, creativo, crítico, que construye con los otros; o un sujeto individualista, dependiente, pasivo, sin criterio, sometido a los designios que otros determinen por él y para él.

Esto hace pensar que para transformar este sistema de opresión y explotación del hombre por el hombre, es necesario formar cuadros políticos, hombres y mujeres que revolucionen el pensamiento dominante, que reflexionen sobre su realidad, y la transformen, para lo cual debe formarse a las familias, como entes transformadores, que reestructuren sus pautas de crianza, las historias y los mitos, usos y costumbres que circulan en la sociedad y que los medios perpetúan en pro de limitar el cambio, de darle continuidad a los limitantes. Hoy, América Latina es el lugar donde se ha constituido un laboratorio crítico del pensamiento neoliberal. En esta primera década del siglo XXI se están operando transformaciones que deben cimentarse, procesos que deben profundizarse también a través de estrategias educativas que acompañen la constitución de los nuevos sujetos históricos (Báez, 2008).

\section{Metodología}

El Plan de Desarrollo Distrital "Bogotá Humana 2012-2016" estableció el eje 1: una ciudad que supera la segregación y la discriminación. La no segregación de la población más vulnerable busca garantizar el desarrollo integral de la primera infancia, implementado sobre los riesgos en seguridad alimentaria, valoración nutricional, prevención de enfermedades, cultura del cuidado y del buen trato, y acciones pedagógicas desde el arte, la literatura, exploración del medio y juego para el desarrollo de los niños.

De esta manera se diseñó, a partir de la no segregación, el proyecto Ámbito Familiar 735 de la SDIS, que inicia como un plan piloto en Bosa para todas las localidades (Marín y Piza, 2016, p. 37). En este, las personas reciben atención de especialistas directamente en sus casas: equipos interdisciplinarios conformados por maestros, psicosociales, nutricionistas, talleristas y trabajadoras sociales atienden de forma integral a niños entre los 0 y 3 años y sus familias, que por algún motivo no pueden estar en 
los jardines infantiles, para prestarles atención en educación, nutrición, salud, cultura y acompañamiento psicosocial en su casa, en su barrio.

Para esto se planearon sesiones de fortalecimiento pedagógico para capacitar al equipo de profesionales que interviene con los participantes del proyecto, en los cuales se trazó el curso de acción frente a la implementación del programa a partir de la educación popular de Paulo Freire, y en la experiencia profesional de la psicóloga Rosalba Ávila, funcionaria de la SDIS, del Equipo Técnico Educación Inclusiva, Diversa y de Calidad.

Es importante destacar que el proceso pedagógico está en permanente deconstrucción y reconstrucción del conocimiento en un sistema cíclico que se plantea en la ruta pedagógica, la cual consta de cuatro estaciones: "Conozcámonos", "Reconozcámonos", "Diseñemos", "Implementemos". El proceso se inicia activando la ruta pedagógica en la identificación de los participantes en recorridos territoriales en sectores priorizados donde se conocen a las madres gestantes y niños de 0 a 3 años (SDIS, s.f.).

Las maestras tienen la función de acompañar el desarrollo integral de los niños mediante tres encuentros pedagógicos domiciliarios, uno cada semana, según se programe con la madre del niño, cada uno de una hora. En estos se trabaja desde la individualidad de la familia, desde su privacidad, atendiendo a sus características y necesidades particulares, con el fin de fortalecer los lazos afectivos entre madre e hijo, aumentar la comunicación y fomentar el papel activo de los padres en la crianza de sus hijos.

- Conozcámonos sugiere partir de exploración de lo propio, de una lectura de realidad instituyente y reflexiva desde los actores sociales asumidos como sujeto productores de conocimiento.

- Reconozcámonos consiste en la representación gráfica de las relaciones de distinto tipo, que están presentes en un momento determinado entre el conjunto de actores, permitiendo ver las relaciones en una red más compleja y próxima a la realidad social. Los imaginarios, prejuicios, ideas y expectativas que se presentan por la intervención pedagógica donde se puede observar el papel de la madre como educadora, el papel del Estado frente a los programas sociales y los modos de acción de los participantes.

- Diseñemos, desde los mapas relacionales, analiza críticamente las posibilidades transformadoras, a partir del diseño colectivo de estrategias que incidan en el desarrollo y potenciación de cada niño, el diálogo y negociación de todos los saberes y prácticas, y que los sujetos actores de la propuesta redefinan cada práctica y cada comprensión.

- Implementemos retorna a la realidad para realizar y concretar la práctica y el saber colectivo construido, que transforme, en los actores, las condiciones y potencie el desarrollo de capacidades de los niños, sus familias y sus comunidades (SDIS, s.f.).

Para que la ruta pedagógica cumpla su ciclo circular, es necesario la planeación oportuna de la intervención pedagógica, entendida como "el proceso de establecer objetivos y escoger el medio más apropiado para el logro de los mismos antes de emprender la acción" (Goodstein, 1998, p. 43). Se realiza, entonces, un diagnóstico desde la lectura de realidades, narraciones, historias de vida, intereses, sueños, creencias y el análisis del contexto, para luego diseñar y formular una estrategia particular puesto que no se puede homogenizar la población, ya que cada uno de los actores tiene diversos modos de vida, es necesario especificar objetivos y definir las acciones a seguir para poder implementar en el desarrollo de acciones planificadas y la evaluación.

Así, se abre paso a la autoevaluación crítica del proceso de implementación de las prácticas educativas y quehacer pedagógico de los maestros, a la luz de los acuerdos de orden epistemológico, pedagógico y metodológico, concertados. Este proceso favorece un mejoramiento en las prácticas y una constante reflexión frente a la intervención pedagógica y la formación de las madres como educadoras y su participación ciudadana.

Los encuentros tanto grupales como pedagógicos siempre van dirigidos al niño como agente principal, y a su familia como apoyo inmediato, en estos se tratan temáticas que abarcan el desarrollo 
del niño en cuanto a nutrición, hábitos de higiene, amor propio, estimulación de acuerdo con su edad y el potenciamiento de sus habilidades y destrezas.

En la planeación de los Encuentros Pedagógicos Domiciliarios siempre se trata de transformar las condiciones del niño, se establece un propósito mensual que busca potenciar, acompañar, resignificar y aprender en familia. Se describe la experiencia pedagógica planeada, la cual debe ser intencionada y que dé respuesta al trabajo realizado con el niño, la familia o gestante, teniendo en cuenta las habilidades, capacidades, intereses de los participantes para potenciar su desarrollo.

Por lo que implica:

1. El tema y su razón.

2. El desarrollo didáctico (proceso transformador).

3. Actividad de compromiso ("tarea").

Por último, se diligencian los respectivos formatos manejados por la SDIS para el seguimiento del proceso y evaluación de la intervención pedagógica, en cada una de las actividades realizadas con los participantes.

Complementando dichos encuentros en el domicilio se realizan dos encuentros pedagógicos grupales, de tres horas cada uno, en los que se hace una lectura de realidades y necesidades, que a su vez permite la activación de rutas con el componente psicológico o nutricional en pro de la restitución de los derechos del niño y sus familias, o el mejoramiento de su calidad de vida. Además, dentro de estos se pretende generar un diálogo de saberes entre los padres participantes, con el fin de propiciar la transformación y construcción de saberes nuevos en la crianza de sus hijos; también, se busca que los niños interactúen de forma activa con sus padres y otros niños de edades similares; que fortalezcan su confianza, sus habilidades comunicativas y su deseo de explorar el mundo que los rodea. Con el fin de trascender en una comunidad generalmente enajenada por procesos de educación tradicionales, toman parte del discurso en un relativismo cultural, haciendo activa su participación como sujeto de derecho y ciudadanos.

De esta forma, se plantearon encuentros que permitían la participación de la madre; a través de cuentos infantiles se fomentaba la reflexión del papel de la mujer en la sociedad y en el hogar, atendiendo como primera medida sus saberes propios, para construir a partir de allí nuevos saberes que les permitieran identificar los aspectos a mejorar o cambiar en pro de su propio beneficio, sin dejar de lado la participación del niño. Por ejemplo, si planteábamos la temática de buenos hábitos alimenticios, primero indagábamos por los conocimientos previos de la madre, a través de juegos de roles, narraciones o dramatizaciones; luego, surgían opiniones encaminadas a la buena alimentación de sus hijos, por lo que se destaca su rol como madres, que través del ejemplo podían crear buenos hábitos en sus niños, si ellas se alimentan sanamente, con frutas, verduras y alimentos preparados en el hogar. Así verían un cambio en sus cuerpos, en sus mentes, en su salud, y además podrían contagiar el deseo de probar una fruta o una verdura en sus hijos.

Luego, replanteamos la forma de acceder a las familias, a las madres como sujetos principales del hogar, y evidenciamos la necesidad de aportar al cambio de sus imaginarios de mundo, para que a partir de los encuentros tanto domiciliarios como grupales no solo atendieran el desarrollo de los niños, en cuanto a las temáticas mencionadas anteriormente, sino que además, formaran a la madre políticamente, empoderando su voz, haciendo que se autorreconozca como un sujeto de derecho con poder para actuar.

\section{Resultados}

En primera medida, las maestras tenían que indagar la lectura de realidades desde los aspectos propios del niño, su nivel de desarrollo, sus destrezas o necesidades primarias, y todo aquello que lo circundaba, como su núcleo familiar, las costumbres de padres, sus creencias, cómo se comunicaban e interactuaban en su diario vivir, con el fin de generar encuentros cercanos a ellos, que les permitieran construir herramientas para mejorar o satisfacer aquellos limitantes. Entre ellos se evidenció un patrón general en las participantes del programa, puesto que para varias mujeres de la localidad de Bosa viven su día a día, o sobreviven a lo que puede Ilamarse su condición de vida. Condición que para muchos es causada por su fertilidad 
ininterrumpida y su deseo de agrandar su familia, o en muchos casos, por su falta de proyección y empoderamiento social.

Los embarazos a temprana edad, la desescolaridad, el desempleo, la violencia intrafamiliar son problemáticas latentes que manifiestan la falta de acción por parte del Estado en la población más vulnerable, un círculo vicioso en la desatención social y el desconocimiento de derechos por parte de las participantes al programa.

Fue así como en reflexiones suscitadas en los encuentros, las participantes mostraron cómo sus ideales se vieron transformados al convertirse en madres y formar una familia; sin darse cuenta, su rol como madre ocupó toda su atención y determinó por alguna razón lo que sería su futuro. La opinión de cada participante reiteraba lo importante que son sus hijos, y cómo cambió su proyección frente a la vida, siendo señaladas por sus familias y la sociedad, manifestando el menosprecio por su condición económica y de género, y la falta de oportunidades que tenían para salir adelante.

Estos planteamientos permitieron retomar las ideas iníciales en las que el dinero determinaba su vida; el factor económico otorga poder, puesto que quien aporta decide y quien consume hace caso, pese a no estar de acuerdo con la opinión de quien toma la decisión. Por esta razón, el apoyo nutricional (bono) que proporciona la SDIS suele ser tan importante para las familias, pues este es un indicador, en alguna medida, de que ellas también pueden ser partícipes del mantenimiento del hogar.

Este hecho genera una dependencia desesperada por aquel aporte monetario, ya que se arraiga la idea del Estado de bienestar como una caridad casi que obligada, en la que las familias no solo deben demostrar unas condiciones que indican su necesidad de consumismo, como: condición de desplazamiento, bajos ingresos económicos, tener más de un niño menor de 3 años, tener hijos con bajo peso, hogares con madres cabezas de hogar o con solo un aportante económico que no alcance a cubrir las necesidades del núcleo familiar; también deben cumplir con cierta asistencia a los encuentros programados por el programa para garantizar su formación, la cual, en muchos casos, podría limitarse solo al asistencialismo.
En un principio no se evidenciaron mayores cambios; las madres seguían viendo a las maestras como aquellos sujetos de poder, que les suministraban no solo un saber sino el derecho a un bono. Con el paso del tiempo, encuentro tras encuentro, fue evidente el avance en la comunicación, las familias empezaron a dejar de tener miedo a opinar, crearon grupos en sus redes sociales para recordar las fechas de los encuentros, para compartir sus dudas, para apoyarse mutuamente; empezaron a verse como madres activas en el desarrollo de sus niños, y como sujetos con voz, con la capacidad para opinar, criticar, cuestionar y cambiar aspectos de sus vidas.

Se evidenció cómo, a través de cada charla, identificaban aspectos en común entre ellas, como la necesidad de terminar el bachillerato, la falta de comunicación en el hogar, el deseo de proveerse sus propias cosas, lo que generó un cambio en sus imaginarios, pues dejaron de ver a las maestras como un agente de poder, para verlas como un ejemplo a seguir, como unos sujetos en los cuales apoyarse. Dejaron de ver su voz silenciada, puesto que en cada encuentro se tenían cuenta sus opiniones, sus creencias, lo que generó una relación dialógica en la que ellas aportaban a la constante formación docente, mientras las maestras les proporcionaban las herramientas para hacer fuerte su voz y su pensamiento.

En las tablas 1 y 2 se muestran algunas de las experiencias generadas en los hogares de los niños durante los encuentros tanto domiciliarios como grupales.

Es clave dentro de esta transformación pedagógica el proceso de formación de lectores, el cual nos aportó herramientas valiosas, pues la alfabetización en la comunidad genera admiración, respeto por la palabra del otro. También propició que entre ellas mismas sus diálogos fueran más fluidos; la motivación por la lectura en familia les otorgó un reconocimiento más como las primeras formadoras, como el ejemplo a seguir, ya que si ellas valoran y leen un libro, así mismo sus hijos lo harán, pueden enriquecer sus saberes y viajar por esa frontera indómita donde se crean mundos posibles a través de la imaginación, mundos equitativos, inclusivos, mundos de acción ciudadana. 
Tabla 1. Experiencias encuentros pedagógicos domiciliarios (EPD).

\begin{tabular}{|c|c|c|c|c|}
\hline \multicolumn{5}{|c|}{ Encuentros pedagógicos domiciliarios } \\
\hline No. & Encuentro/Tema & $\begin{array}{c}\text { Objetivo } \\
\text { general }\end{array}$ & Acciones & Resultados \\
\hline 1 & $\begin{array}{l}\text { Lo estás logrando } \\
\text { hijo } \\
\text { (Realizado a un } \\
\text { niño de } 2 \text { años de } \\
\text { edad) }\end{array}$ & $\begin{array}{l}\text { Promover y } \\
\text { fortalecer la } \\
\text { construcción } \\
\text { de vínculos } \\
\text { de cuidado } \\
\text { sensible y de } \\
\text { interacción } \\
\text { afectuosos con } \\
\text { el niño y los } \\
\text { miembros de la } \\
\text { familia. }\end{array}$ & $\begin{array}{c}\text { EPD 1: Se realiza una actividad } \\
\text { de agilidad física con el cuidador, } \\
\text { donde el niño puede reflejar el } \\
\text { desarrollo psicomotor: } \\
\text { Coordinación mano-ojo, } \\
\text { desplazamientos, saltos, lanzamiento } \\
\text { de pelota. } \\
\text { En cada ejercicio se alientan y se } \\
\text { reconocen los avances del niño. } \\
\text { EPD 2: Se realiza el rompecabezas } \\
\text { de corazón pintando con témpera, } \\
\text { escribiendo los sentimientos } \\
\text { generados en acciones del niño, } \\
\text { como: alegría, sorpresa, tranquilidad, } \\
\text { rabia, miedo, tristeza. Se destaca } \\
\text { la calma y la tranquilidad como } \\
\text { modo de reacción frente al niño y } \\
\text { sentimientos propios del adulto. }\end{array}$ & $\begin{array}{l}\text { La madre reconoció el avance } \\
\text { en las acciones físicas de su hijo, } \\
\text { aplaudió cada uno de sus logros, } \\
\text { se sonreía y manifiesta sentirse } \\
\text { orgullosa por las capacidades } \\
\text { y potencialidades que se han } \\
\text { desarrollado en su hijo a nivel } \\
\text { físico y cognitivo. El niño manifestó } \\
\text { alegría a través de gritos, aplausos } \\
\text { risas, se generó un espacio de } \\
\text { admiración y de mimos de parte } \\
\text { de la madre a su hijo, el cual fue } \\
\text { recíproco. La madre reconoció que } \\
\text { ha tenido una visión negativa de su } \\
\text { hijo por temor a que se lastime o } \\
\text { creerlo incapaz por la edad. }\end{array}$ \\
\hline 2 & $\begin{array}{l}\text { El tesoro de mamá } \\
\text { (Realizado a una } \\
\text { niña de } 5 \text { meses } \\
\text { de edad) }\end{array}$ & $\begin{array}{c}\text { Desarrollar } \\
\text { la relación } \\
\text { materno-filial } \\
\text { a través de } \\
\text { masajes y } \\
\text { caricias que } \\
\text { propicien su } \\
\text { desarrollo } \\
\text { afectivo, } \\
\text { cognitivo y } \\
\text { motriz. }\end{array}$ & $\begin{array}{l}\text { EPD 1: Se presentan sonajeros y } \\
\text { peluches y tarjetas de contrastes } \\
\text { de líneas negras y rojas para que la } \\
\text { bebé observe y levante la cabeza y } \\
\text { los siga con la vista. } \\
\text { EPD 2: Se generan espacios de } \\
\text { contacto físico madre e hija con un } \\
\text { masaje desde el pie hasta la cadera } \\
\text { susurrándole canciones de cuna y } \\
\text { palabras cariñosas. } \\
\text { EPD 3: Se presenta un libro álbum y } \\
\text { se lee con diferentes entonaciones. }\end{array}$ & $\begin{array}{c}\text { Se evidencia el agrado de la bebé } \\
\text { frente a las actividades destacando } \\
\text { el contacto físico de la mamá con } \\
\text { la niña en los masajes y caricias, } \\
\text { como también sus sonrisas y } \\
\text { balbuceo, respondiendo a los } \\
\text { halagos y canciones de cuna que le } \\
\text { cantaba la mamá. Ella manifiesta su } \\
\text { preocupación frente al desarrollo } \\
\text { de su hija y lo que ella le puede } \\
\text { aportar, en lo cual puede reconocer } \\
\text { su rol fundamental en la crianza de } \\
\text { su hija. }\end{array}$ \\
\hline 3 & $\begin{array}{l}\text { La historia de tu } \\
\text { vida } \\
\text { (Realizado con } \\
\text { una niña de } 3 \\
\text { años) }\end{array}$ & $\begin{array}{l}\text { Estimular los } \\
\text { lazos afectivos } \\
\text { de la niña } \\
\text { por medio } \\
\text { de pequeñas } \\
\text { narraciones } \\
\text { sobre su origen. }\end{array}$ & $\begin{array}{l}\text { EPD 1: Se genera un espacio de } \\
\text { diálogo con la madre donde nos } \\
\text { cuenta cómo fue el embarazo, si fue } \\
\text { planeado y las reacciones familiares, } \\
\text { se realiza una reconstrucción } \\
\text { fotográfica de los hechos. } \\
\text { EPD 2: Se observan las fotografías } \\
\text { familiares del antes, durante y } \\
\text { después del embarazo, y se da un } \\
\text { diálogo sobre el rol de madre y de } \\
\text { mujer. } \\
\text { EPD 3: Se elabora una cartelera con } \\
\text { la madre sobre sus planes a corto, } \\
\text { mediano y largo plazo. }\end{array}$ & $\begin{array}{c}\text { En las narraciones de la historia } \\
\text { familiar se generó nostalgia, } \\
\text { tristeza; salieron algunas lágrimas, } \\
\text { pues la madre arrepentida } \\
\text { reconoció que fue un embarazo } \\
\text { no deseado y que lloró durante la } \\
\text { gestación, después del parto pudo } \\
\text { enamorarse de su hija, por lo cual } \\
\text { decidió brindarle su tiempo y todo } \\
\text { su amor queriendo compensar } \\
\text { esos primeros meses de tristeza. } \\
\text { Ella siente que la niña es distante } \\
\text { por esta causa, reconoce su rol } \\
\text { como mujer y madre, y cuánto está } \\
\text { dispuesta a dar por el bienestar de } \\
\text { su hija. }\end{array}$ \\
\hline
\end{tabular}

Fuente: elaboración propia. 
Tabla 2. Experiencias de encuentros pedagógicos grupales (EPG).

\begin{tabular}{|c|c|c|c|c|}
\hline \multicolumn{5}{|c|}{ Encuentros grupales } \\
\hline No. & Encuentro/Tema & $\begin{array}{c}\text { Objetivo } \\
\text { general }\end{array}$ & Acciones & Resultados \\
\hline 1 & $\begin{array}{l}\text { Los sentimientos } \\
\text { hacia los niños y } \\
\text { las niñas }\end{array}$ & $\begin{array}{l}\text { Generar } \\
\text { conciencia } \\
\text { acerca de los } \\
\text { sentimientos } \\
\text { que despiertan } \\
\text { en los } \\
\text { adultos las } \\
\text { características } \\
\text { de los niños } \\
\text { que tienen a su } \\
\text { cargo. }\end{array}$ & $\begin{array}{l}\text { - Dinámica de expresión de } \\
\text { sentimientos con los niños. } \\
\text { - Preguntas orientadores acerca de } \\
\text { cómo manifiestan sus emociones } \\
\text { o sentimientos con sus hijos. } \\
\text { - Reflexiones sobre casos creados } \\
\text { por los participantes. } \\
\text { - Planteamiento de estrategias para } \\
\text { manejar de mejor manera sus } \\
\text { emociones y sentimientos. }\end{array}$ & $\begin{array}{l}\text { A través del diálogo entre pares, } \\
\text { cada participante reflexionó sobre } \\
\text { las reacciones que tienen en su } \\
\text { diario vivir, además pudieron } \\
\text { construir entre todos estrategias } \\
\text { para manejar sus emociones y } \\
\text { expresar sus sentimientos de } \\
\text { manera asertiva, con el fin de } \\
\text { mejorar sus relaciones afectivas y } \\
\text { acercarse más a sus hijos. }\end{array}$ \\
\hline 2 & $\begin{array}{l}\text { La familia y la } \\
\text { comunicación } \\
\text { asertiva }\end{array}$ & $\begin{array}{l}\text { Reconocer la } \\
\text { importancia } \\
\text { de la familia y } \\
\text { promover entre } \\
\text { las participantes } \\
\text { formas más } \\
\text { efectivas de } \\
\text { comunicar sus } \\
\text { necesidades } \\
\text { dentro del } \\
\text { núcleo familiar. }\end{array}$ & $\begin{array}{l}\text { - Lectura del cuento "El divorcio } \\
\text { de papá y mamá". } \\
\text { - Narraciones previas sobre: } \\
\text { familia, la importancia de esta en } \\
\text { el desarrollo de los niños y las } \\
\text { formas de comunicación que se } \\
\text { manejan dentro de ella. } \\
\text { - Discusión orientada hacia: qué } \\
\text { es la familia; tipos de familias; } \\
\text { formas de comunicación dentro } \\
\text { de la familia; el papel de los } \\
\text { niños dentro de la familia. }\end{array}$ & $\begin{array}{l}\text { Los participantes se permitieron } \\
\text { pensar en el significado de familia, } \\
\text { a través de sus experiencias de } \\
\text { niños y de su realidad como } \\
\text { padres, lo que permitió que } \\
\text { reflexionaran en torno al concepto } \\
\text { ideal de familia y de qué forma } \\
\text { ellos pueden acercarse o alejarse } \\
\text { a este a partir de sus acciones } \\
\text { cotidianas. }\end{array}$ \\
\hline 3 & $\begin{array}{c}\text { Concepción de } \\
\text { mujer }\end{array}$ & $\begin{array}{l}\text { Sensibilizar } \\
\text { a los } \\
\text { participantes } \\
\text { sobre el } \\
\text { significado de } \\
\text { ser mujer y } \\
\text { sobre el papel } \\
\text { que pueden } \\
\text { ejercer las } \\
\text { mujeres dentro } \\
\text { de la sociedad, } \\
\text { más allá de los } \\
\text { prototipos. }\end{array}$ & $\begin{array}{l}\text { Dinámica el espejo, para } \\
\text { evidenciar la visión de cada una de } \\
\text { sí misma. } \\
\text { Historia de la conmemoración de } \\
\text { Día de la Mujer, con la ayuda de } \\
\text { imágenes. } \\
\text { Discusión sobre el significado de: } \\
\text { violencia; desprecio; marginación; } \\
\text { cordialidad; amistad; solidaridad; } \\
\text { respeto; diversidad. } \\
\text { Creación del concepto de mujer } \\
\text { a partir de sus imaginarios y las } \\
\text { reflexiones suscitadas. }\end{array}$ & $\begin{array}{l}\text { Las madres manifestaron su deseo } \\
\text { de hacer escuchar su voz, de salir } \\
\text { de la represión para dar su opinión } \\
\text { frente a las decisiones del hogar, de } \\
\text { sus hijos y de su vida. Comentaron } \\
\text { las expectativas que tenían de su } \\
\text { vida antes de ser madres y ahora } \\
\text { como ejes fundamentales del } \\
\text { hogar, y aunque los cambios en sus } \\
\text { metas son evidentes, sus hijos se } \\
\text { convierten en un factor importante } \\
\text { a la hora de tomar riesgos y de } \\
\text { motivarse a continuar su vida como } \\
\text { sujetos activos. }\end{array}$ \\
\hline
\end{tabular}

Fuente: elaboración propia.

Se logró fortalecer el pensamiento crítico de las madres, el empoderamiento de su palabra como sujeto de derecho, a partir de la pedagogía crítica, puesto que con el simple hecho de escuchar y motivar la discusión, junto con la reflexión propia y constante de la realidad inmediata de todas las participantes, empezaron a formarse políticamente, a ser conscientes de su participación en su calidad de vida. En ese sentido, si su postura continuaba siendo pasiva y consumista, dirigida por el bienestar generado por un bono alimentario, continuarían subsanando de manera superficial el malestar causado por la falta de dinero o de oportunidades, mientras que si modificaban su posición, su 
pensamiento, y sacaban de su interior los miedos, prejuicios y el conformismo, empezarían a resurgir en su mente los sueños de niñez y juventud, aqueIlos ideales de conquistar el mundo, de triunfar, de ser autosuficientes y de hacer conocer su voz por sus habilidades.

Dichos cuestionamientos gestaron un cambio en ellas, se empoderaron creando una madre lideresa que recolectaba las opiniones de todas en horarios externos a los de los encuentros, para sugerir temáticas de trabajo, para dialogar con las madres lideresas de otros grupos, para participar y luego pasar la voz a las demás madres, de los saberes propagados en las capacitaciones por parte de la SDIS; entre ellas intercambiaban experiencias, dudas, problemáticas, se informaban a dónde acudir para restablecer sus derechos, se agruparon de acuerdo con sus empatías o necesidades unas para inscribirse a cursos gratuitos del SENA, con el fin de adquirir herramientas que les permitieran tener un ingreso económico, para laborar como digitadoras

o estilistas medio tiempo; otras, enfocaron sus fuerzas en la creación de sus propios negocios, como la venta de arepas, salpicón, hacer manicura a domicilio, construir elementos en goma EVA (foami) o material reciclado para vender.

Aspectos como este hicieron que el apoyo nutricional pasara a ser solo eso, un apoyo, puesto que el verdadero eje conductor del programa se convirtió en reunirse para hablar sobre lo que le pueden aportar a sus hijos y sobre lo que pueden aportarse a sí mismas, como seres importantes y partícipes en la sociedad. En consecuencia, se deja de lado la visión negativa de pobreza, en la que el Estado debía ser su proveedor constante, y tomando esa postura política de cambio, de decisión, de ejercer sus derechos sociales de manera activa, en la que se desea transformar la sociedad a partir de la transformación de realidades, en la que el consumismo de ayudas sociales está mandado a recoger, y en la que el auge es la producción de ciudadanos activos, que constantemente buscan herramientas para mejorar su calidad de vida.

Por otro lado, la transformación de imaginarios también implicó un cambio en las pautas de crianza de las madres, a medida que se realizaban los encuentros, las participantes eran más conscientes de su rol como madres, como primeras formadoras, pero no desde la metodología del premio y el castigo, sino desde parámetros de crianza afectuosa, en la que prima el amor y la comunicación como agente corrector y el ejemplo como guía. Para lograr esto, se realizaban dramatizaciones en las que las madres podían reflexionar sobre problemáticas dadas en torno a crianzas con violencia y sin canales de comunicación, lo que propiciaba que las participantes realizaran comparaciones internas con sus anécdotas de vida y replantearan sus visiones, en pro de resolver de forma adecuada dichos conflictos, y de aplicarlos posteriormente en su cotidianidad.

\section{Conclusiones}

- Generar espacios donde las madres perciban la importancia de mejorar sus pautas de crianza, las formas de comunicación con su familia, o la manera de estimular el desarrollo de sus hijos, ya que inicialmente lo sentían como algo ajeno, impuesto y propio de las maestras por lo que no les generaba dentro de su concepción mayor beneficio para sí mismas, motivo por el cual se limitaban asistir para obtener una firma que garantizara la entrega del apoyo nutricional o mal Ilamado "bono".

- Esta experiencia, dentro del espacio laboral que viven las maestras, enriqueció el pensamiento pedagógico, puesto que evidenció la importancia de educar a la familia, de transformar los espacios en los cuales crecen los niños, a partir del fomento de la postura política de las madres y cuidadoras, invisibilizando su necesidad programada de esperar apoyos económicos con el ideal de salir así de sus dificultades.

- Es significativo reconocer el rol del pedagogo en la educación no formal, en la educación comunitaria o en espacios no convencionales, donde no solo se impacta la vida del participante, sino la de cada una de las familias con las cuales se construye la visión política, a su vez que se propicia el reconocimiento como individuos activos dentro de la comunidad a la cual pertenecen. Las madres participantes y los niños del proyecto 735 Ámbito Familiar en la localidad de Bosa. 
- El discurso de poder del pedagogo puede partir del reconocimiento del otro, como igual; por ello, es oportuno generar espacios de diálogo de saberes, donde cada cual aporta su punto de vista desde su experiencia, para así transformar a través de la contraposición de dichos saberes, los imaginarios que han regido sus comportamientos y actitudes en busca del bien común.

- Se estableció un estado de comunión y construcción de conocimiento mutuo en el que entraron en juego los conocimientos populares de la comunidad y los propios conceptos de las maestras, para consolidar una relación dialógica, entre los padres y maestras, dentro de la cual intervinieron creencias, reflexiones, ideales, que permitieron, a pesar de las limitaciones generalizadas de este tipo de población, despertar el deseo interno de mejorar su calidad de vida y superar sus dificultades infundadas.

- Esta experiencia puede ser entendida como una respuesta a esa educación bancaria que hace referencia Paulo Freire en su pedagogía, pues la educación convencional es caracterizada por ser autoritaria y unidimensional, es decir, rechaza la crítica y niega el diálogo y la reflexión, razón por la que dentro del proyecto Ámbito Familiar, se intentó aplicar la educación popular para permitirles a los sujetos tomar conciencia de su condición, reconociendo sus habilidades y necesidades, para transformar su realidad en algo positivo para sí.

- La educación política es una responsabilidad del pedagogo, aprovechando los espacios de aprendizaje de las personas, pues es se reconoce como sujeto de derecho y puede enriquecer su conocimiento frente al Estado y las instituciones que lo acogen, para que así ejercer sus derechos y deberes de manera justa, inclusiva, equitativa y democrática.

- Desde este punto de vista, es necesario reconocer el papel vital de las madres como primeras educadoras, y no subestimar su condición por su nivel educativo o estrato socioeconómico, puesto que en ellas es posible encontrar las bases para la formación integral de nuestra infancia. Por esto, lo ideal es traspasar los saberes escolares y construir una educación emocional, una pedagogía desde el amor y la esperanza, que permita una crianza llena de momentos gratos y felices en los niños, y que genere sujetos activos, con pensamiento crítico, con la capacidad de movilizar masas, y de transformar ambientes en pro del avance de su comunidad.

\section{Referencias}

Alcaldía Mayor de Bogotá. (2009). Diagnóstico local con participación social 2009-2010. Recuperado de: http://www.saludcapital.gov.co/ sitios/VigilanciaSaludPublica/Diagnosticos $\% 20$ Locales/07-BOSA.pdf

Báez, F. (2008). El saqueo cultural de América Latina. Madrid: Debate.

Castoriadis, C. (1993). La institución imaginaria de la sociedad. Vol. I. Marxismo y teoría revolucionaria. Buenos Aires: Tusquets.

Ciancio, A. M. (s.f.). Las relaciones familiares en el contexto de la crisis en el contexto de la crisis en la ciudad del Rosario. Las mujeres en las estrategias de sobrevivencia.

Dirección de Epidemiología y Demografía del Ministerio de Salud. (2015). Análisis de situación de salud (ASIS), Colombia, 2015. Recuperado de: https://www.minsalud.gov.co/sites/rid/Lists/ BibliotecaDigital/RIDE/VS/ED/PSP/asis-2015. pdf

Donzelot, J. (2007). La invención de lo social. Ensayo sobre la declinación de las pasiones políticas. Buenos Aires: Nueva Visión. Recuperado de: https://laelectrodomestica.files.wordpress. com/2014/07/donzelot-la-invencion-de-lo-social.pdf

Freire, E. (s.f.). Medición del trabajo no remunerado. Recuperado de: http://www.dane.gov.co/ files/noticias/uso tiempo freire.pdf?phpMyAd$\underline{\min =a 9 t i c q 8 r v 198 \mathrm{vhk} 5 \mathrm{e} 8 \mathrm{cck} 52 \mathrm{r} 1}$

Freire, P. (1970). Acción cultural para la libertad. Buenos Aires: Tierra Nueva.

Freire, P. (1993). Cartas para el que pretende enseñar. Buenos Aires: Siglo XXI. Recuperado de:https://docs.google.com/document/d/1aRP-Wf5CkjHOVN5E4hRUQ9i5FNpVQz6ZnygPB U4Fuk/edit

Freire, P. (1997). La educación como práctica de la libertad. México: Siglo XXI. Recuperado 
de: https://www.textosenlinea.com.ar/academicos/Freire\%20-\%20La\%20educacion \%20 como\%20practica\%20de\%20la\%20libertad. pdf

Gallardo, H. (2006). Sujeto y cultura política popular en América Latina. Ciclo de conferencias. Costa Rica. Recuperado en: http:// www.heliogallardo-americalatina.info/index. php?option=com

Geldstein, R. (1994). Familias con liderazgo femenino en sectores populares. En: C. H. Wainerman (comp.). Vivir en familia (p. 70). Buenos Aires: Unicef; Losada.

Ley No. 1413 de 2010. Diario Oficial No. 47.890 de noviembre de 2010. Recuperado de: http:// www.secretariasenado.gov.co/senado/basedoc/ ley 1413 2010.html

Marín, L. y Piza, L. (2016). Propuesta de mejoramiento de la gestión de calidad en la práctica pedagógica del proyecto 735 Ámbito Familiar de la Secretaría Distrital de Integración Social de la localidad de Bosa. Recuperado de: http://repository.udistrital.edu.co/bitstream/11349/2763/1/ PizaAguillonLauraLiliana2016.pdf

Montagut, T. (2000). Política social. Una introducción. Barcelona: Ariel.

Pichon, E. (1984). El proceso creador: Del psicoanálisis a la psicología social. Tomo III. Buenos Aires: Nueva Visión.

Ramírez, A. (7 de abril de 2015). Solo hay una mujer por cada nueve hombres en cargos altos. El Tiempo. Recuperado de: http://www.eltiempo. com/archivo/documento/CMS-15526840

Ramírez, G. (2011). Economía del cuidado y retos de la política pública. Recuperado de: http:// www.dane.gov.co/files/noticias/uso tiempo gloria ramirez.pdf?phpMyAdmin=a9ticq8rv198vhk5e8cck52r11

Redacción Nacional. (22 de septiembre de 2014). Alarmantes cifras de embarazo adolescente en Colombia. El Espectador. Recuperado de: http://www.elespectador.com/noticias/salud/ alarmantes-cifras-de-embarazo-adolescente-colombia-articulo-518121

Reveco, O. (2002). La relación jardín infantil-familia desde lo cotidiano. Seis dimensiones para su fortalecimiento. Congreso Europeo: Aprender a ser, aprender a vivir juntos. Santiago de Compostela, diciembre 2001. Recuperado de: www.oei.es/historico/inicial/articulos/relacion jardin familia.pdf

Rosemberg, F. (2009). Educación popular con eje en el desarrollo infantil. Itinerario de viaje por el territorio Madres. Buenos Aires: Clacso.

Secretaría Distrital de Integración Social (SDIS). (s.f.). Caja de herramientas. Ámbito Familiar. Recuperado de: http://cajadeherramientasformacion.blogspot.com.co/

Secretaría Distrital de Integración Social (SDIS). (2013). Proyecto 735: Desarrollo integral de la primera infancia en Bogotá. Recuperado de: http://intranetsdis.integracionsocial.gov. co/anexos/documentos/1.3 proc direc estrategico/(13122013)735\%20Desarrollo\%20 integral $\% 20 \mathrm{de} \% 201 \mathrm{a} \% 20$ primera $\% 20$ infancia $\% 20$ con $\% 20$ corte $\% 20 a \% 2022 \% 2011 \% 20$ 2013.pdf

Secretaría Técnica del Consejo Distrital de Política Social. (2014). Política Pública de Infancia y Adolescencia. Recuperado de: http://www. culturarecreacionydeporte.gov.co/sites/default/files/convocatorias cartillas y anexos/ anexo politica publica de infancia y adolescencia. informe de seguimiento enero - junio 2013.pdf

Silva, J. (1997). Los padres, primeros educadores de sus hijos. Guía para la producción de materiales de autoaprendizaje. Oficina Regional de Educación de la Unesco para América Latina y el Caribe - Oreal/Unesco. Santiago de Chile. Recuperado de http://unesdoc.unesco.org/images/0011/001177/117708So.pdf 